\title{
Decisions and the involvement of cancer patient survivors: a moral imperative
}

\author{
Gabriella Pravettoni ${ }^{1,2}$ \\ Ilaria Cutica ${ }^{1,2}$ \\ Simona Righetti' \\ Ketti Mazzocco',2
}

'Department of Oncology and Hematology, University of Milan, ${ }^{2}$ Applied Research Division for Cognitive and Psychological Science, European Institute of Oncology, Milan, Italy
Correspondence: Gabriella Pravettoni Department of Oncology and Hematology, University of Milan, Via Festa del Perdono, 7, 20122 Milan, Italy Tel +39250320140

Email gabriella.pravettoni@unimi.it
This article was published in the following Dove Press journal:

Journal of Healthcare Leadership

7 December 2016

Number of times this article has been viewed

Purpose: The aim of this study was to review the experiences of direct involvement in patient survivorship for treatment and research.

Methods: This is a narrative-focused review of the following two recent experiences of patient involvement: the Chordoma Foundation and the Triple Negative Breast Cancer Foundation.

Results: These two examples represent concrete experiences that patients have built to favor a real involvement in the care and treatment of tumors. These experiences are profoundly modifying how cancer research is conducted and draw attention to the psychosocial dimensions of health care.

Conclusion: These examples represent the new scenario in which modern medicine faces completely new challenges, copes with new needs, and cooperates with new health care professionals.

Implications: Involving patients in a new perspective raises practical and ethical challenges for organizations to work together, for health providers to be professionally skilled and for the government to promote safeguarding policies.

Keywords: patient empowerment, patients' association, empowerment, skills, codesign techniques, cancer

\section{Introduction}

Over the past 2 decades, the nature of cancer patients and their needs have changed significantly. ${ }^{1}$ Progress in technology and medical sciences, such as the human genome, screening techniques, and surgical procedures, has given patients a choice in terms of the treatment and care of different types of tumors. ${ }^{2}$ However, this progress has also given rise to a different kind of a cancer patient, one who has increasingly complex needs and depends on a high level of technology for his/her survival. ${ }^{3}$ Nevertheless, modern medicine still sustains a strong biomedical approach, missing the "social nature of cancer", or in other words, the social capital, characterized by both the patient's physical and human components. ${ }^{4}$ The need to consider the patients' knowledge, experiences, and needs is not a mere ethical position. It also has clinical consequences. As Sox et $\mathrm{al}^{5}$ posit, health care professionals work most of the time under uncertain conditions, where information is limited and ambiguous and the consequences of treatment choice are estimated on a probability-based reasoning. ${ }^{6,7}$ In addition, utilities and values are affected by subjective past experiences, beliefs, and interpersonal contexts. From this perspective, important information is locked inside the patient and hidden to the professional's eyes. 
This uncertainty is particularly evident in (but not limited to) rare diseases (not only in oncological setting), ${ }^{8-10}$ where not enough clinical evidence is available. In such cases, caring for patients must be expanded to include a further, and in a certain way, new and challenging concept: working with patients.

In the following section, some significant examples are reported where the direct involvement of patients in clinical studies and dissemination has been relevant. This article does not represent a systematic review as the available examples are limited and not structured in every country. This is more a narrative-focused review of the main experiences regarding collaboration between patients and clinical investigators at an international level.

\section{Patients as special collaborators}

The example of Josh Sommer, executive director of a research organization called the Chordoma Foundation, ${ }^{11}$ completely embodies this approach. Diagnosed with a chordoma, a rare bone cancer for which there was a low cure rate, a 7-year life-expectancy, very little research, and no approved drugs, Sommer believed that the patient can have the power to make a difference in research for the cure of chordoma and other fatal diseases. Thanks to technology, he rounded up patients with the same cancer and all researchers working on it, optimizing the resources earlier scattered around the world, increasing awareness of the problem, and breaking down barriers to progress.

In this perspective, as shown by Stacchiotti et al, ${ }^{12}$ patients are not only passive care receivers but also special collaborators who can proactively help clinicians and researchers reduce the aforementioned uncertainty. Important research has been conducted on discovering chordoma therapies, for example, the utility of some enzymes in the mechanism of this tumor. ${ }^{13}$ Clinical practice guidelines were also drawn up in collaboration with the Chordoma Foundation with patients playing an active role and were published in an international peer-reviewed scientific journal.

Similarly, the Triple Negative Breast Cancer (TNBC) Foundation organized a meeting of investigators and advocates to assess the state of current clinical and translational research on triple-negative breast cancer and published the main recommendations regarding future prospects for research into this breast cancer subtype. ${ }^{14}$

These examples are significant and they propose a new methodology for conducting research and publishing data. However, these examples are not yet consolidated. Future research should implement the gap that exists between traditional research and the new way of conducting studies with the active involvement of patients.
The first step entails empowering the patients by providing high-quality up-to-date information. The second involves brokering collaborations with patients by taking advantage of their skills, knowledge, and desire to exert control on their health condition.

In present society, however, the shift from a paternalistic approach where the patient is a passive receiver of treatment to a patient-centered paradigm in which the patient is an active participant is still a slow process. The utility of the patient's perspective as a reflection of his/her personal values, expectations, and needs ${ }^{15}$ is still far from being an integral part of modern culture. Take for example the plethora of studies on physician-patient communication; it is well-known that the most effective communication paradigm is the one that reduces the knowledge and influences the asymmetry between physicians and patients (ie, only the doctor knows everything) and that the medical discussion has to be collaborative, ie, the doctor gives a frame to clarify the clinical picture and following decisions and the patient states information on his/ her health status, preferences, and previous knowledge about the cancer and its treatments. ${ }^{15}$ In this way, all the relevant treatment possibilities are shown, and these possibilities are discussed by both the physician and the patient within the medical consultation. ${ }^{16}$ Such a paradigm is effective because it allows the physician to generate the shared knowledge indispensable for establishing the patient's involvement and for effectively bringing about a shared decision practice. ${ }^{17}$ Notwithstanding, this does not happen as frequently as patients would like. There still exists a constant gap between what patients want and what they get with respect to engagement in health care, whereas between $70 \%$ and $80 \%$ of patients strongly want their physician to take into account their desires and hopes and values and to engage them in the decision process, and less than half report that this is what happens in reality. ${ }^{18}$ In addition, in a worldwide survey on cancer patients, ${ }^{19}$ most of the surveyed patients desired more knowledge and involvement concerning treatment and care for cancer; for example, $\sim 40 \%$ of patients considered that patient participation in decision making in cancer is inadequate; in the European countries included, the percentage of dissatisfaction was $\sim 25 \%$ in some countries, such as Italy, and somewhat higher (58\%) in some countries, such as Germany. In a number of countries, it was considered that there is inadequate knowledge available to patients about the nature of specific types of tumors. On this point, European opinions ranged from a low of $31 \%$ in Italy to $54 \%$ in France who judged that not enough knowledge is accessible. In relation to the decisionmaking process, the study identified a considerable majority of patients (75\% in France and Germany, $73 \%$ in Italy, and $72 \%$ 
in the UK) who evaluate as extremely important the fact that patients and their families should be the leaders in decision making about treatment options and timing.

Moreover, several studies focusing on the assessment of the most common conceptualizations about cancer found that most people know very little about it. ${ }^{20}$ To be in a position to reason and actually take decisions about their medical care, patients need to be given by their physician a correct "set of knowledge" about their illness. A systematic review of 86 clinical trials ${ }^{21}$ found that offering patients clear and evident information leads to 1) an enhanced level of knowledge of treatment options and medical guidelines, 2) more precise probabilities of benefits and risks, 3) being able to evaluate a number of choices more compatible with own health status and in line with their system of values, and 4) stable patient satisfaction. Patients with capacities in information seeking are those who better comprehend what is communicated, can better evaluate the appropriateness of their condition and are able to choose medical treatment in a more appropriate way.

A clear understanding of their actual health situation is important to patient involvement, and a more thorough understanding of medical knowledge in the general population is essential to improving health, particularly that of underprivileged populations. Poor health literacy is a political challenge, which should be greatly taken into account and addressed by health care operators and decision makers ${ }^{22}$ and warrants a higher profile in the political agenda. In some cases, private organizations attempt to fill the gap. A good example is the TNBC. ${ }^{23}$ This foundation was established in 2006 in honor of Nancy Block-Zenna, a young patient who died from triple-negative breast cancer (one of the most aggressive forms of breast cancer, which is presented in $\sim 15 \%-20 \%$ of breast cancer population). In response to Nancy's prognosis, her close friends founded the TNBC Foundation to promote knowledge and support research in this field. One of the Foundation's goals was to ignite interest in the study of TNBC among researchers, physicians, and educators. Today, the world is very different TNBC wise than when Nancy was diagnosed. Women with TNBC are no longer the wallflowers at the breast cancer prom. And all over the world, researchers are focusing on target therapies for this subtype of breast cancer. This is the result of an increased public awareness, and undoubtedly, the TNBC Foundation has played a role in it.

\section{Conclusion and implications}

Patient involvement has been formulated in a plethora of documents and guidelines from various international bodies. ${ }^{24-27}$ However, laws and declarations in and of themselves automatically do not make patient involvement in practice, nor do they automatically frame health systems in a patientcentered perspective. Involving patients in a new perspective raises practical and ethical challenges for organizations to work together, for health providers to be professionally skilled, and for the government to promote protecting policies. $^{28}$ In health care, the term "co-design" refers to patients and carers working in partnership with health providers to improve clinical research, care modalities, and service provision. ${ }^{29}$ Co-design techniques, such as the experience-based co-design (EBDC), involve collecting important experiences and data from patients and health care operators through qualitative techniques (such as in-depth interviews, observations, and focus groups), categorizing key points, so-called "touch points" (ie, areas with a relevant emotional impact) and allocating positive or negative feelings. ${ }^{30-32}$ The method was created to acquire knowledge and solutions that offer patients a better experience for dealing with cancer. It is an approach that enables health care operators and patients (and other service users) to co-design services for health care, together in partnership. Such collaboration may determine important practical consequences; for example, in the field of rehabilitation, it has been shown that the involvement of patients, who share experiences, everyday difficulties, and the way to process information, has resulted as a decisive factor in calibrating and modulating intervention for cognitive disabilities. ${ }^{33,34}$ Similar results have been shown in the field of physical rehabilitation for chronic pain. ${ }^{35,36}$ Patients are precious resources whereby important research questions may be addressed and advances in treatment may be promoted. In addition, the advent of tailored medical treatments has brought about a greater need for supplementary scientific backing in order to evaluate the complex medical decision support data. In addition, the medical rationale needs to be communicated to the patient efficiently and effectively. Fortunately, clinical decision-making tools are making great strides. On the one hand, assessment tools may assist physicians in combining and examining large amounts of data (the results of laboratory exams, diagnostic tests, scientific literature, etc) and also in distributing such results among other health care operators. On the other hand, personalized tools may help physicians with data regarding the cognitive aspects of each patient, which will contribute to a more precise knowledge of expectations, fears, attitudes to risk, and health literacy. This should assist the physician in future interactions with the patient, improving communication efficacy. ${ }^{37}$ The advent of telemedicine and telecommunications is a further factor that allows patients and health providers to improve communication, exchange knowledge, and create power ${ }^{21}$ both in the decision-making process and in disease and treatment management. Furthermore, in 
this regard, professionals cannot overlook the need to design such tools alongside and with the patient, who is after all, the final stakeholder.

Other important examples are related to the improvement of patient-doctor communication, especially in the field of clinical trials. It is well known that at an international level, the percentage of hypothetically qualified patients recruited to clinical trials is low, blocking the development of research evidence that may guide and enhance clinical practice. ${ }^{37,38}$ The UK clinical research networks have been operating to increase quality, importance, and focus of research in their National Health Service (NHS), and initial outcomes in oncology have yielded evidence that the recruitment rate to cancer clinical trials has considerably increased. ${ }^{19}$ The majority of patients are quite interested in participating in randomized clinical trials (RCTs). Many of those initially refuse because of randomization; however, when the physician is able to explain the study in an accessible way and is able to take into account any possible fears and doubts, then the patients generally accept. ${ }^{39}$ These data demonstrate the relevance and need for clear communication and information to support RCT participation. Evidence-based training courses should be available to help with this.

Cancer patient welfare is starting to become a key policy area, whereby governments are recognizing cancer patients as central to these plans. ${ }^{32}$ This is an ethical response to the plight of many of the patients in the community. It is also acknowledged that they have increasingly unique needs, and collaborative working and innovative thinking are called for on the part of health care professionals and politicians in order to see their needs met. However, much still remains to be done to bring care and involvement in-line with the rhetoric. It is unclear as to how involvement will be measured where there are no distinct plans and where the forthcoming financial climate over the next few years looms bleakly. As demonstrated, there is an undeniably strong ethical imperative to care for these patients, but it is one fraught with difficulties.

\section{Disclosure}

The authors report no conflicts of interest in this work.

\section{References}

1. Johnston PG, Pinedo HM. The high tide of cancer research in Europe. Oncologist. 2011;16(5):539-542.

2. Jain KK. Role of nanobiotechnology in developing personalized medicine for cancer. Technol Cancer Res Treat. 2005;4(6):645-650.

3. Lawler M, Le Chevalier T, Murphy MJ, et al. A catalyst for change: the European cancer patient's bill of rights. Oncologist. 2014;19(3):217-224.

4. Purushotham A, Cornwell J, Burton C, Stewart D, Sullivan R. What really matters in cancer? Putting people back into the heart of cancer policy. Eur J Cancer. 2013;49(7):1669-1672.
5. Sox HC, Higgins MC, Owens DK. Medical Decision Making. 2nd ed. Chichester, UK: John Wiley \& Sons, Ltd; 2013.

6. Baldi PL, Iannello P, Riva S, Antonietti A. Socially biased decisions are associated to individual differences in cognitive reflection. Stud Psychol. 2013;55:265-271.

7. Renzi C, Riva S, Masiero M, Pravettoni G. The choice dilemma in chronic hematological conditions: why choosing is not only a medial issue? A psycho-cognitive perspective. Crit Rev Oncol Hematol. 2016;99:134-140.

8. Mangiafico L, Perja M, Fusco F, Riva S, Mago D, Gringeri A. Safety and effectiveness of raltegravir in patients with haemophilia and anti-HIV multidrug resistance. Haemophilia. 2011;18(1):108-111.

9. Riva S, Cutica I, Pravettoni G. Is there evidence for neurocognitive dysfunctions in patients with postnatal HIV infection? A review on the cohort of hemophilia patients. Front Hum Neurosci. 2014;8:470.

10. Riva S, Cutica I, Krampe C, et al. A cohort pilot study on HIV-associated neuropsychological impairments in hemophilia patients. Front Hum Neurosci. 2015;9:313.

11. CHORDOMA Foundation [homepage on the Internet]. Available from: http://www.chordomafoundation.org. Accessed April 25, 2016.

12. Stacchiotti S, Sommer J; Chordoma Global Consensus Group. Building a global consensus approach to chordoma: a position paper from the medical and patient community. Lancet Oncol. 2015;16(2): e71-e83.

13. Sommer J, Itani DM, Homlar KC, et al. Methylthioadenosine phosphorylase and activated insulin-like growth factor-1 receptor/ insulin receptor: potential therapeutic targets in chordoma. J Pathol. 2010;220(5):608-617.

14. Schneider BP, Winer EP, Foulkes WD, et al. Triple-negative breast cancer: risk factors to potential targets. Clin Cancer Res. 2008;14(24): 8010-8018.

15. Gorini A, Pravettoni G. P5 medicine: a plus for a personalized approach to oncology. Nat Rev Clin Oncol. 2011;8(7):444.

16. Schwarz A. The Man Working to Cure His Own Cancer. Available from: http://www.theatlantic.com/health/archive/2014/03/the-man-workingto-cure-his-own-cancer/284091/. Accessed November 10, 2016.

17. Lucchiari C, Pravettoni G. Cognitive balanced model: a conceptual scheme of diagnostic decision making. J Eval Clin Pract. 2012;18(1): $82-88$.

18. Cutica I, Vie GM, Pravettoni G. Personalised medicine: the cognitive side of patients. Eur J Int Med. 2014;25(8):685-688.

19. Alston C, Paget L, Halvorson G, et al. Communicating with Patients on Health Care Evidence. Washington, DC: Discussion Paper, Institute of Medicine; 2012. Available from: https://nam.edu/wp-content/ uploads/2015/06/VSRT-Evidence.pdf.

20. Downs JS, de Brui W, Fischhoff B, Hesse B, Maibach E. How people think about cancer: A mental models approach. In: Handbook of risk and crisis communication. Mahwah, NJ: Erlbaum; 2009:507-524.

21. Stacey D, Bennett LL, Barry MJ, et al. Decision aids for people facing health treatment or screening decisions. Cochrane Database Syst Rev. 2011;5(10):CD001431.

22. Coulter A, Ellins J. Effectiveness of strategies for informing, educating and involving patients. BMJ. 2007;335(7609):24-27.

23. TRIPLE NEGATIVE BREAST CANCER FOUNDATION [homepage on the Internet]. Available from: http://www.tnbcfoundation.org/. Accessed April 25, 2016.

24. Casali PG, Bruzzi P, Bogaerts J, Blay JY; Rare Cancers Europe (RCE) Consensus Panel. Rare Cancers Europe (RCE) methodological recommendations for clinical studies in rare cancers: a European consensus position paper. Ann Oncol. 2014;26(2):300-306.

25. World Health Organization [webpage on the Internet]. WHO Patient Safety - Programme Areas. Copenhagen: WHO Regional Office for Europe; 2012. Available from: http://www.who.int/patientsafety/about/ programmes/en/index.html. Accessed April 25, 2016.

26. Kondylakis H, Koumakis L, Tsiknakis M, et al. Smart recommendation services in support of patient empowerment and personalized medicine. In: Multimedia Services in Intelligent Environments. Springer International Publishing 2013:39-61. 
27. Kondylakis H, Koumakis L, Genitsaridi E, et al. IEmS: a collaborative environment for patient empowerment, IEEE 12th International Conference on BioInformatics and BioEngineering, BIBE; 2012; Article 6399770: Pg 535-540

28. Riva S, Mazzocco K, Pravettoni G. Better outcomes for cancer patients using telemedicine: health-related quality of life (HrQoL) and empowerment. In: Gatti G, Pravettoni G, Capello F, editors. Tele-Oncology. Switzerland: Springer; 2015:23-37.

29. Riva S, Monti M, Iannello P, Pravettoni G., Schulz PJ, Antonietti A. A preliminary mixed-method investigation of trust and hidden signals in medical consultations. PLoS One. 2014;9(3):e90941.

30. Robert G, Cornwell J, Locock L, Purushotham A, Sturmey G, Gager M. Patients and staff as codesigners of healthcare services. BMJ. 2015;350:g7714.

31. Sangiorgi D. Transformative services and transformative design. Int J Design. 2011;5:29-40.

32. Gorini A, Mazzocco K, Gandini S, Munzone E, McVie G, Pravettoni G. Development and psychometric testing of a breast cancer patient profiling questionnaire. Breast Cancer. 2015;7:133-146.

33. Burnet K, Benson J, Earl H, Thornton H, Cox K, Purushotham AD A survey of breast cancer patients' views on entry into several clinical studies. Eur J Cancer Care (Engl). 2004;13(1):32-35.
34. Oliveri S, Incorpora C, Genevini M, et al. Clinical investigation of cognitive styles in patients with acquired brain damage. Neuropsychol Rehabil. 2012;22(3):362-373.

35. Incorpora $\mathrm{C}$, Oliveri $\mathrm{S}$, Genevini $\mathrm{M}$, et al. Visual and verbal styles in patients with cognitive deficits: a preliminary study. Int $J$ Neurosci. 2010;120(8):557-564.

36. Riva S, Camerini AL, Allam A, Schulz PJ. Interactive sections of an Internet-based intervention increase empowerment of chronic back pain patients: randomized controlled trial. J Med Internet Res. 2014;16(8):e180.

37. Schulz PJ, Hartung U, Riva S. Causes, coping, and culture: a comparative survey study on representation of back pain in three Swiss language regions. PLoS One. 2013;8(11):e78029.

38. Robert G, Cornwell J. Designing the future: rethinking policy approaches to measuring and improving patient experience. $J$ Health Serv Res Policy. 2013;18:66-67.

39. Pravettoni G, Mazzocco K, Gorini A, Curigliano G. Understanding cognitive processes behind acceptance or refusal of phase I trials. Crit Rev Oncol Hematol. 2016;100:69-73.

40. Bergenmar M, Molin C, Wilking N, Brandberg Y. Knowledge and understanding among cancer patients consenting to participate in clinical trials. Eur J Cancer. 2008;44(17):2627-2633.
Journal of Healthcare Leadership

\section{Publish your work in this journal}

The Journal of Healthcare Leadership is an international, peer-reviewed, open access journal focusing on leadership for the health profession. The journal is committed to the rapid publication of research focusing on but not limited to: Healthcare policy and law; Theoretical and practical aspects of healthcare delivery; Interactions between healthcare and society and evidence-based practices;

\section{Dovepress}

Interdisciplinary decision-making; Philosophical and ethical issues; Hazard management; Research and opinion for health leadership; Leadership assessment. The manuscript management system is completely online and includes a very quick and fair peer-review system. Visit http://www.dovepress.com/ testimonials.php to read real quotes from published authors. 